\title{
Switching to low tar cigarettes: are the tar league tables relevant?
}

\author{
ROGER G RAWBONE
}

From the Research Division, Gallaher Ltd, Belfast

ABSTRACT Representative samples of smokers of regular middle tar and regular low tar cigarettes responded to a questionnaire concerning their smoking habits and participated in a blind product test, returning 24 hour butt collections from the smoking of both middle tar and low tar cigarettes. An estimate of the mouth intake of tar derived from a measurement of filter nicotine confirmed partial compensation by the low tar smokers relative to the middle tar smokers, resulting in $32 \%$ lower tar delivery rather than the $46 \%$ expected from the standard machine values. Most middle tar smokers $(98 \%)$ achieved an estimated tar delivery within or below that of the league table middle tar band when smoking middle tar cigarettes, while $70 \%$ of low tar smokers had a mouth intake of $10.49 \mathrm{mg}$ or below within the low tar band when smoking low tar cigarettes. These results support the current tar league tables as a guide to the smoker in selecting a lower delivery cigarette.

For comparison of smoke deliveries different kinds of cigarettes are smoked by machines according to a standard regimen. ${ }^{12}$ There is a $35 \mathrm{ml}$ bell shaped flow profile puff of 2 seconds' duration every minute down to a standard butt length; the resultant smoke delivery is then determined by standard analytical techniques, ${ }^{2}$ the most commonly measured components being tar (usually presented as particulate matter, water and nicotine free-PMWNF), nicotine, and carbon monoxide.

The results of such analyses, determined by the Laboratory of the Government Chemist, form the basis of the tar, nicotine, and carbon monoxide (league) tables published by the Departments of Health in the United Kingdom since $1973 . .^{3-5}$ In these tables cigarette products are classified on the basis of tar yield per cigarette as low tar $(0-10.49 \mathrm{mg})$, low to middle $\operatorname{tar}(10.50-16.49 \mathrm{mg})$, middle $\operatorname{tar}(16.50-22.49 \mathrm{mg})$, middle to high tar (22.50-28.49 mg), and high tar (28.50 mg or more). Cigarettes have changed considerably during the past decade. Over the period 1972 to October 1983 the number of low tar brands on the market has

Address for reprint requests: Dr Roger G Rawbone, Research Division, Gallaher Ltd, Virginia House, Henry Street, Belfast BT15 1JE.

Accepted 4 June 1984 increased from 6 to 37 and the number of low to middle and middle tar brands from 81 to 107 , while middle to high tar brands have decreased from 13 to 3 and high tar brands have been totally eliminated. ${ }^{5}$ Accompanying these changes there has been a fall in the sales weighted average tar delivery from $21 \mathrm{mg}$ to about $15 \mathrm{mg} .^{67}$

It is now widely recognised, however, that human smokers do not smoke like the standard smoking machine and that their patterns of smoking behaviour, which ultimately define the smoke exposure dose, may vary according to the product being smoked. Studies have shown that during the smoking of a low tar cigarette the smoking pattern is more intensive than with a middle tar cigarette, so that the reductions in yield that would be expected from reference to standard machine values might be offset by the change in smoking pattern, with little or no resultant reduction in intake. $^{89}$

The tendency of smokers to change smoking behaviour when smoking different cigarettes puts into question the relevance of the Government tar league tables as a guide to tar exposure. The present study was designed to assess the mouth intake (delivery) of tar in demographically representative populations of middle and low tar smokers. Tar delivery was measured indirectly by butt nicotine analysis, and the results were compared with the published league tables. 


\section{Methods}

Two hundred middle tar and two hundred low tar smokers were recruited from several regions of the UK by an independent market research agency (Research Bureau Ltd, London). The objective was to match the demographic profiles of middle and low tar smokers as identified by an independent continuous population survey (MAS Survey Research Ltd, London) covering the whole of Great Britain, in which a sample of 2400 adults are drawn at random every week from electoral registers for personal interview. The characteristics matched were age, sex, social class (based on occupation of head of household), and cigarette consumption. Each smoker was sent a supply of middle and of ventilated low tar cigarettes, manufactured to commercial specification but digit coded and in plain packs. Subjects were asked to smoke each product exclusively over a full 24 hour period and to put the cigarette butts in tins provided. The order in which respondents were asked to smoke the two cigarettes was randomised. The completed 24 hour butt collections, with a questionnaire covering smoking habits in detail, were then returned to the research agency.

Each 24 hour butt collection was treated in the following way. After the number of butts had been counted individual butt lengths were measured and the residual tobacco was stripped from the filter, which was then split longitudinally to facilitate nicotine extraction. A random sample of 10 filters (or the total collection when cigarette consumption was less than this number) was taken for determination of nicotine content. After extraction with propan-2-ol and sulphuric acid the nicotine was analysed by the standard technique agreed between the Government Chemist and the tobacco industry. ${ }^{2}$

The results for each smoker thus comprised a 24 hour cigarette consumption, butt length, and filter nicotine for the smoking of both a middle and a low tar cigarette.

Nicotine delivery to the smoker can be readily estimated from the measurement of filter nicotine if the efficiency of the filter for nicotine retention is known. Thus

$$
\text { Nicotine delivery }=\frac{\text { Filter nicotine }(1-F)}{F},
$$

where $F$ is the fraction of nicotine retained by the filter. The measure of filter efficiency is normally derived from an analysis of filter nicotine and nicotine delivery during standard machine smoking and the result obtained is then assumed to be a constant and applied to human smoked filter nicotine figures to give the human delivery. Filter efficiency, is not, however, a constant, varying widely according to butt length and puff flow profile, ${ }^{1011}$ which during human smoking are very different from the standard smoking machine values. In the current study, because individual subjects' smoking patterns could not be recorded, a "human smoking" nicotine retention efficiency has been defined for each product by calculating the average result obtained from the measurement of filter nicotine and nicotine delivery for 20 different human smoking profiles obtained, for each cigarette, in a separate laboratory study using the human smoking puff recorder and duplicator system. ${ }^{12}$

Once we have defined, from the filter (butt) nicotine analysis, the nicotine delivery to the smokers this can be related to the tar delivery on the basis of the product tar:nicotine ratio. Like filter efficiency this ratio is dependent on the smoking pattern so the figure derived from standard machine smoking is likely to be different from that obtained by the smoker. An approximation for the human tar:nicotine ratio has therefore been defined by the direct measurement of tar and nicotine delivery from the same duplicated human smoking profiles as in the estimation of efficiency above.

\section{Results}

One hundred and thirty four middle tar and the same number of low tar smokers returned complete 24 hour butt collections from the smoking of both low and middle tar products, the response rate being $67 \%$ from both groups. Table 1 shows the comparison of these respondents with the target demographic profiles defined by the MAS survey taken just before the study. Some differences are apparent, with a higher than expected response from women in the middle tar group and a greater response from the higher social class groups in the low tar group. In addition, both middle and low tar groups are biased towards smokers with a high cigarette consumption.

Smoke analyses from the standard machine smoking of both products, with the filter nicotine retention efficiencies and tar:nicotine ratios derived from the duplication of human smoking profiles, are given in table 2 . Table 3 presents the results of the 24 hour butt collections from both middle and low tar smokers when smoking each of the two products. Nicotine and estimated tar deliveries were significantly lower during the smoking of the low tar cigarettes than during the smoking of middle tar cigarettes in both groups of smokers. There were no differences in cigarette consumption. Histograms 
Table 1 Comparison of the middle and low tar study populations with the target demographic profiles obtained through an independent market research survey

\begin{tabular}{|c|c|c|c|c|}
\hline & \multicolumn{2}{|l|}{ Low tar } & \multicolumn{2}{|l|}{ Middle tar } \\
\hline & $\begin{array}{l}\text { Study population } \\
(\%) \\
(n=134)\end{array}$ & $\begin{array}{l}\text { Market research survey } \\
(\%) \\
(n=1284)\end{array}$ & $\begin{array}{l}\text { Study population } \\
(\%) \\
(n=134)\end{array}$ & $\begin{array}{l}\text { Market research survey } \\
(\%) \\
(n=5973)\end{array}$ \\
\hline \multicolumn{5}{|l|}{ Sex } \\
\hline $\begin{array}{l}\text { Male } \\
\text { Female }\end{array}$ & 31 & 31 & 46 & 53 \\
\hline $\begin{array}{c}\text { Female } \\
\text { (a) }\end{array}$ & 69 & 69 & 54 & 47 \\
\hline \multicolumn{5}{|l|}{ Age (years) } \\
\hline $\begin{array}{l}16-24 \\
25-34\end{array}$ & $\begin{array}{r}6 \\
16\end{array}$ & $\begin{array}{r}5 \\
15\end{array}$ & $\begin{array}{l}10 \\
25\end{array}$ & $\begin{array}{l}21 \\
22\end{array}$ \\
\hline $35-44$ & 19 & 18 & 23 & 17 \\
\hline $45-64$ & 46 & 43 & 34 & 30 \\
\hline $65+$ & 13 & 19 & 8 & 11 \\
\hline \multicolumn{5}{|l|}{ Social class (head of household) } \\
\hline Professional and clerical & 58 & 45 & 26 & 27 \\
\hline Skilled, unskilled, on state benefit & 42 & 55 & 74 & 73 \\
\hline \multicolumn{5}{|l|}{ Cigarette consumption } \\
\hline $\begin{array}{c}1-9 \\
10-19\end{array}$ & 36 & 36 & 34 & $\begin{array}{l}14 \\
34\end{array}$ \\
\hline $20-29$ & 44 & 31 & 44 & 37 \\
\hline $30+$ & 7 & 10 & 14 & 14 \\
\hline
\end{tabular}

Table 2 Smoke delivery, filter efficiency, and tar: nicotine ratio of the low and middle tar cigarettes studied

\begin{tabular}{lcc}
\hline STANDARD MACHINE SMOKING CONDIMONS & Low tar & Middle tar \\
Butt length (mm) & 30 & 29 \\
PMWNF (mg) & $9 \cdot 3$ & $17 \cdot 2$ \\
Nicotine (mg) & 0.96 & $1 \cdot 33$ \\
Carbon monoxide (mg) & 9.9 & $16 \cdot 2$ \\
HUMAN SMOKING condinons & 46.6 & $39 \cdot 7$ \\
Mean filter nicotine efficiency (\%) & $9 \cdot 5$ & 10.7 \\
Tar (PMWNF): nicotine ratio & & \\
\hline
\end{tabular}

PMWNF-particulate matter, water and nicotine free.

Table 3 "Butt" analyses from both middle and low tar smokers, each smoking the two study cigarettes

\begin{tabular}{|c|c|c|c|c|c|c|}
\hline & \multicolumn{3}{|c|}{ Low tar smokers (mean $(S D))$} & \multicolumn{3}{|c|}{ Middle tar smokers (mean $(S D)$ ) } \\
\hline Product smoked: & Low tar & & Middle tar & Low tar & & Middle tar \\
\hline $\begin{array}{l}\text { No of cigarettes per day } \\
\text { Butt length }(\mathrm{mm}) \\
\text { Nicotine delivery (mg) } \\
\text { Tar delivery (mg) }\end{array}$ & $\begin{array}{l}17 \cdot 5(8 \cdot 1) \\
30 \cdot 5(4 \cdot 1) \\
1 \cdot 00(0 \cdot 32) \\
9 \cdot 5(3 \cdot 0)\end{array}$ & $\begin{array}{l}-\mathrm{NS}- \\
-{ }^{*}- \\
-{ }^{* *}- \\
-{ }^{* *}-\end{array}$ & $\begin{array}{l}17 \cdot 1(8 \cdot 6) \\
31 \cdot 3(4 \cdot 8) \\
1 \cdot 23(0 \cdot 39) \\
13 \cdot 2(4 \cdot 2)\end{array}$ & $\begin{array}{l}16 \cdot 8(7 \cdot 4) \\
31 \cdot 1(4 \cdot 0) \\
1 \cdot 03(0 \cdot 35) \\
9 \cdot 8(3 \cdot 4)\end{array}$ & $\begin{array}{l}-\mathrm{NS}- \\
-\mathrm{NS}- \\
-{ }^{* *-} \\
-{ }^{* *}-\end{array}$ & $\begin{array}{l}16 \cdot 5(7 \cdot 3) \\
31 \cdot 0(4 \cdot 1) \\
1 \cdot 31(0 \cdot 39) \dagger \\
14 \cdot 0(4 \cdot 1) \dagger\end{array}$ \\
\hline
\end{tabular}

${ }^{*} \mathrm{p}<0.01 ;{ }^{* *} \mathrm{p}<0.001$-paired $t$ test: within smoker, low tar smoking versus middle tar smoking.

$\mathrm{Tp}<\mathrm{U} \cdot \mathrm{UU}$ i- unparred $t$ test: low tar smokers and low tar product versus middle tar smokers and middle tar product. When they were smoking the same kind of cigarette there was no significant difference between the two groups of smokers with respect to nicotine delivery or tar delivery.

comparing the distributions of estimated tar intake for the low tar smokers smoking the low tar cigarette and the middle tar smokers smoking the middle tar cigarette are shown in the figure. The delivery to middle tar smokers from middle tar cigarettes ranged from 1.95 to 28.3 (mean 14.0 ) $\mathrm{mg}$, while the delivery to low tar smokers from low tar cigarettes ranged from 2.07 to 21.9 (mean 9.5 ) $\mathrm{mg}$. For both groups the values appear skewed, with clustering to the left of the mean. Table 4 shows how these distributions of intake relate to the different tar categories within the government league tables. Ninety eight percent of middle tar smokers have an estimated tar delivery at or below that of the upper boundary of the middle tar definition of $22.49 \mathrm{mg}$, while $70 \%$ of low tar smokers have deliveries at or below $10.49 \mathrm{mg}$ tar. 


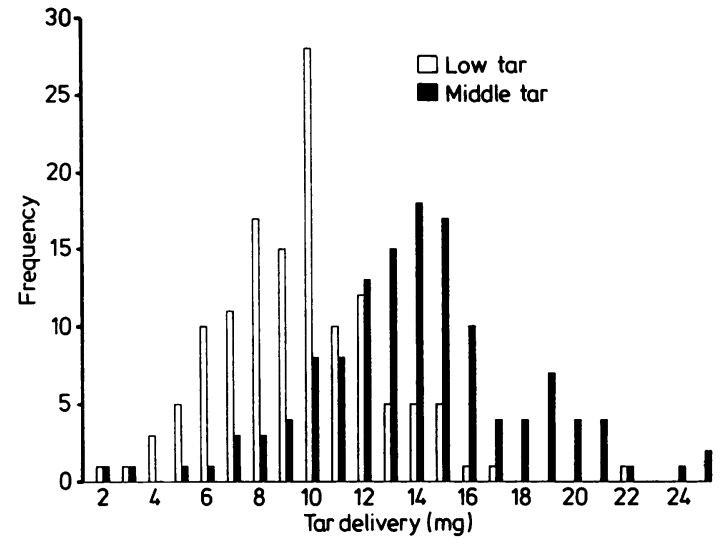

Frequency histogram of the extimated tar delivery to middle tar smokers smoking middle tar cigarettes (solid bars, $n=130)$ and low tar smokers smoking low tar cigarettes (open bars, $n=131$ ).

Table 4 Relationship between the tar league table bands (UK Health Departments) and the estimated tar deliveries to low tar smokers smoking a low tar cigarette and middle tar smokers smoking a middle tar cigarette

\begin{tabular}{llc}
\hline $\begin{array}{l}\text { Government tar delivery } \\
\text { band }(\mathrm{mg})\end{array}$ & $\begin{array}{l}\text { \% low tar } \\
\text { smokers }\end{array}$ & $\begin{array}{l}\text { \% middle tar } \\
\text { smokers }\end{array}$ \\
\hline Low tar <10.5 & $69 \cdot 6$ & $16 \cdot 8$ \\
Low to middle tar $10 \cdot 5-16.49$ & 28.9 & 62.6 \\
Middle tar 16.5-22.49 & $1 \cdot 5$ & $18 \cdot 3$ \\
Middle to high tar 22.5-28.49 & 0 & $2 \cdot 3$ \\
High tar $>28.49$ & 0 & 0 \\
\hline
\end{tabular}

\section{Discussion}

This study was designed to estimate the tar delivery to representative populations of middle and low tar smokers and in so doing assess the relevance of the published tar league tables.

The response rate in both middle and low tar smoker groups of $67 \%$, which is higher than was anticipated on the basis of the experience of the research agency, gave study populations whose characteristics differed in certain respects from the demographic profiles of the populations of large scale market research studies. The data have been gathered from the smoking, over a 24 hour period in a normal environment, of standardised commercial cigarettes that were contained in plain packs. Possibly subjects used their own brands concurrently with the test cigarettes. While these factors might introduce biases into the study it seems unlikely that they will affect the overall conclusions.

In terms of defining the smoke exposure, while a measurement of uptake or retention would have been preferable to that of smoke delivery (mouth intake), there are currently no techniques available for the measurement of uptake which readily lend themselves to a large scale population based study. Indeed, for the direct estimation of tar delivery no method is applicable to the free smoking natural conditions, to which the present study addresses itself. In other large scale studies the authors have attempted to extrapolate to tar retention from the uptake of nicotine and carbon monoxide, commonly used measures of smoke uptake, ${ }^{13}{ }^{14}$ but because of differences in retention characteristics this is not possible with any degree of confidence. These considerations are not critical, however, when discussions are based on smoke delivery, where extrapolation from nicotine to tar has some validity. The estimation of tar delivery also permits a direct comparison with and therefore evaluation of the standard machine smoke tar values, which form the basis of published tar league tables.

Using a programmable smoking machine, Creighton and Lewis have shown ${ }^{10}$ that there are complex main and interaction effects of puff volume, puff profile (shape), and interpuff interval on the deliveries of tar, nicotine, and carbon monoxide; the ratios of deliveries of these components; and the filter retention efficiencies. The application of a mean figure for filter efficiency and for the tar: nicotine ratio to individual smokers, who exhibit a wide range of smoking behaviour, can be valid only if there is no systematic relationship between those variables that affect these measurements and the actual smoke delivery in the context of natural human smoking. This lack of correlation is widely assumed, although there is no published information in its support.

In the present study, based on the mouth intake of nicotine, low tar smokers smoking low tar cigarettes have a nicotine delivery some $24 \%$ lower than middle tar smokers smoking middle tar cigarettes, compared with the expected $28 \%$ reduction based on machine delivery figures; the equivalent figures for tar are $32 \%$ and $46 \%$. The results suggest a $6 \%$ oversmoking of the low tar product relative to the middle tar product. In a comparable study Stepney ${ }^{15}$ reported $30 \%$ oversmoking for similar products but this was in a laboratory based population. This increased intensity in the smoking of low tar products relative to middle tar products results in differences in uptake of measured smoke components that are less than expected on the basis of their standard machine yields. ${ }^{15}$ This has been shown to be due, at least in part, to differences in puffing indices between these groups of smokers. ${ }^{16} 17$

For any smoker the mouth delivery of smoke components will represent the maximum available 
for uptake or retention. Published studies, however, have shown that for individuals the smoke delivery is not directly proportional to the uptake. ${ }^{18}$ Studies in which both mouth delivery and uptake have been measured in the same subjects show a wide variation in results with relative low tar to middle tar product nicotine deliveries of $68 \% \%^{15}$ and $96 \%$ and respective uptake figures, based on 24 hour urinary nicotine, of $67 \%$ and $94 \%$. Despite the variation there is a concordance between relative delivery and uptake, which would suggest the hypothesis that there are no systematic differences between the inhalation patterns of middle and low tar smokers. Further evidence for this hypothesis comes from studies in which direct measurements of inhalation have been made..$^{17} 18$

If there is no difference between the inhalation patterns of middle and low tar smokers then for particulates, where deposition and retention are predominantly functions of inhalation patterns, the differences in tar delivery would be expected to reflect differences in retention. The estimated tar delivery to the low tar smokers smoking low tar cigarettes in the present study is $68 \%$ that of the middle tar smokers smoking middle tar cigarettes and this may well represent the true relative exposure rate.

Cigarette consumption is also a major factor in determining the total smoke exposure for any smoker and the current study, in line with other published large scale studies, ${ }^{1920}$ shows no significant differences between the consumption patterns of the middle and low tar cigarette groups.

Green $^{21}$ has previously reported a wide range of tar deliveries to smokers of brands within any given tar band as defined by the government league tables and this is confirmed in the present study. Of greater relevance, however, is the distribution of tar deliveries within each tar band, which in the present study clearly shows that low tar cigarettes deliver less tar to the smoker than do middle tar cigarettes.

It has recently been stated that the smoker can control the burning and ventilation characteristics of his cigarette either by changing the number of puffs $^{22}$ or by blocking the ventilation holes, ${ }^{23-25}$ manipulations that have the potential for increasing the smoke delivery. If these changes are occurring in practice they do not appear to cause the tar delivery to increase to the degree which has been suggested.

The lower tar delivery from the smoking of low tar cigarettes is further emphasised by the switching of the middle tar smokers to a low tar product for 24 hours in the present study, when a mean estimated reduction of $4.3 \mathrm{mg} \operatorname{tar}(\mathrm{p}<0.001)$ was observed. Of the 134 middle tar smokers, only four achieved a delivery of tar from the low tar product equal to or higher than that of the middle tar product.
For the individual smoker the tar league tables are relevant in that, although they may give no real indication of the absolute tar delivery from the brand being smoked they do indicate the direction of a real change in tar delivery that a smoker may expect when switching between middle and low tar bands despite compensatory changes in smoking behaviour. Overall the results obtained from this study are consistent with the published government tar league tables in showing that for a middle tar cigarette most (98\%) smokers achieve a delivery within or below the middle tar band of 16.50 $22.49 \mathrm{mg}$, while among low tar smokers about $70 \%$ take $10.49 \mathrm{mg}$ or less from their product. Although somewhat arbitrary in terms of the butt length and puff characteristics used, standard smoking machine tar yields appear to reflect the average human mouth intake as estimated in the present study.

\section{References}

' International Organisation for Standardisation. International Standards ISO 3308, ISO 3402. Geneva: ISO, 1977 and 1978.

${ }^{2}$ Rothwell K, Grant CA, eds. Standard methods for the analysis of tobacco smoke. 2nd ed. London: Tobacco Research Council, 1974. (Research paper 11.)

${ }^{3}$ Department of Industry. Smoking and health. In: Reports of the Government Chemist. London: HMSO, 1973, 1974, 1975, 1976, 1978, 1979, 1980, 1981.

${ }^{4}$ Health Departments of the United Kingdom. Tar and nicotine yields of cigarettes. London: HMSO, 1973-81. (Leaflets TN1-49.)

${ }^{5}$ Health Departments of the United Kingdom. Tar, carbon monoxide and nicotine yields of cigarettes. London: HMSO, 1981-3. (Leaflets TCN1-6.)

- Lee PN, ed. Statistics of smoking in the United Kingdom. 7th ed. London: Tobacco Research Council, 1976. (Research Paper 1.)

${ }^{7}$ Independent Scientific Committee on Smoking and Health. Third report of the Independent Scientific Committee on Smoking and Health. London: HMSO, 1983.

${ }^{8}$ Creighton DE, Lewis PH. The effect of different cigarettes on human smoking patterns. In: Thornton $\mathrm{RE}$, ed. Smoking behaviour: physiological and psychological infuences. Edinburgh: Churchill Livingstone, 1978:289-300.

9 Ashton H, Stepney R, Thompson JW. Self-titration by cigarette smokers. Br Med J 1979;ii:357-60.

${ }^{10}$ Creighton DE, Lewis PH. The effect of smoking pattern on smoke deliveries. In: Thornton RE, ed. Smoking behaviour: physiological and psychological infuences. Edinburgh: Churchill Livingstone, 1978:301-14.

"Mumpower RC, Keifer JE. Some factors that affect the filtration of nicotine from cigarette smoke. Tobacco Science 1967;11:144-7.

12 Creighton DE, Noble MJ, Whewell RT. Instruments to measure, record and duplicate human smoking patterns. In: Thornton RE, ed. Smoking behaviour: physiological and psychological infuences. Edinburgh: Churchill Livingstone, 1978:277-88. 
${ }^{13}$ Wald NJ, Idle M, Boreham J, Bailey A. Inhaling habits among smokers of different types of cigarette. Thorax 1980;35:925-8.

14 Russell MAH, Jarvis M, Iyer R, Feyerabend C. Relation of nicotine yield of cigarettes to blood nicotine concentrations in smokers. Br Med J 1980;280:972-6.

${ }^{15}$ Stepney R. Would a medium-nicotine, low-tar cigarette be less hazardous to health? $\mathrm{Br}$ Med J 1981;283:1292-6.

${ }^{16}$ Gust SW, Pickens RW. Does cigarette nicotine yield affect puff volume? Clin Pharmacol Ther 1982;32:418-22.

17 Tobin MJ, Sackner MA. Monitoring smoking patterns of low and high tar cigarettes with inductive plethysmography Am Rev Respir Dis 1982;126:258-64.

${ }^{18}$ Rawbone RG, Murphy K, Tate ME, Kane SJ. The analysis of smoking parameters, inhalation and absorption of tobacco smoke in studies of human smoking behaviour. In: Thornton RE, ed. Smoking behaviour: physiological and psychological infuences. Edinburgh: Churchill Livingstone, 1978:171-94.

${ }^{19}$ Wald NJ, Idle M, Boreham J, Bailey A. The importance of tar and nicotine in determining cigarette smoking habits. J Epidemiol Commun Health 1981;35:23-4.
${ }^{20}$ Garfinkel L. Changes in the cigarette consumption of smokers in relation to changes in tar/nicotine content of cigarettes smoked. Am J Public Health 1979;69:1274-6.

${ }^{21}$ Green SJ. Ranking cigarette brands on smoke deliveries. In: Thornton RE, ed. Smoking behaviour: physiological and psychological infuences. Edinburgh: Churchill Livingstone, 1978:380-8.

${ }^{22}$ Kozlowski L. Tar and nicotine delivery of cigarettes: what a difference a puff makes. JAMA 1981;245:158-9.

${ }^{23}$ Kozlowski LT, Frecker RC, Khouw V, Pope MA. The misuse of "less-hazardous" cigarettes and its detection: hole-blocking of ventilated filters. Am J Public Health 1980;70:1202-3.

${ }^{24}$ Kozlowski LT, Rickert WS, Pope MA, Robinson JC, Frecker RC. Estimating the yield to smokers of tar, nicotine, and carbon monoxide from the "lowest yield" ventilated filter-cigarettes. $\mathrm{Br} J$ Addict 1982;77:159-65.

${ }^{25}$ Lombardo T, Davis J, Prue DM. When low tar cigarettes yield high tar: cigarette filter ventilation hole blocking and its detection. Addict Behav 1983;8:67-9. 